1 Original Research Article

\title{
2 Ploidy dynamics in aphid host cells harboring bacterial symbionts
}

3

4 Tomonari NOZAKI $^{1 *}$, Shuji SHIGENOBU ${ }^{1,2}$

$5{ }^{1}$ Laboratory of Evolutionary Genomics, National Institute for Basic Biology, 38

6 Nishigonaka, Myodaiji, Okazaki, Aichi 444-8585, Japan

$7 \quad{ }^{2}$ Department of Basic Biology, School of Life Science, The Graduate University for

8 Advanced Studies (SOKENDAI), 38 Nishigonaka, Myodaiji, Okazaki, Aichi 444-8585

9 Japan

10

$11{ }^{*}$ Correspondence:

12 Tomonari Nozaki, Laboratory of Evolutionary Genomics, National Institute for Basic

13 Biology, Okazaki, Aichi 444 $\square 8585$, Japan

14 Telephone: $+81-564-55-7670$

15 Email: nozaki.t@ nibb.ac.jp, tomonari64.1.8@gmail.com

16

17

18 ORCID: https://orcid.org/ 0000-0003-4358-8118 $\quad$ (T.N.), https://orcid.org/

$19 \quad 0000-0003-4640-2323$ (S.S.)

22 Key Words: intracellular symbiosis, bacteriocytes, endopolyploidy, aphids, Buchnera

23 aphidicola, DNA-content analysis, confocal microscopy 


\section{Abstract}

26 Aphids have evolved bacteriocytes or symbiotic host cells that harbor the obligate

27 mutualistic bacterium Buchnera aphidicola. Because of the large cell size (approximately

$28100 \mu \mathrm{m}$ in diameter) of bacteriocytes and their pivotal role in nutritional symbiosis,

29 researchers have considered that these cells are highly polyploid and assumed that

30 bacteriocyte polyploidy may be essential for the symbiotic relationship between the aphid

31 and the bacterium. However, little is known about the ploidy levels and dynamics of

32 aphid bacteriocytes. Here, we quantitatively analyzed the ploidy levels in the

33 bacteriocytes of the pea-aphid Acyrthosiphon pisum. Image-based fluorometry revealed

34 the hyper polyploidy of the bacteriocytes ranging from 16- to 256-ploidy throughout the

35 lifecycle. Bacteriocytes of adult parthenogenetic viviparous females were mainly

36 64-128C DNA levels, while those of sexual morphs (oviparous females and males) were

37 consisted of $64 \mathrm{C}$, and 32-64C cells, respectively. During post-embryonic development of

38 viviparous females, the ploidy level of bacteriocytes increased substantially, from 16-32C

39 at birth to $128-256 \mathrm{C}$ in actively reproducing adults. These results suggest that the ploidy

40 levels are dynamically regulated among phenotypes and during development. Our

41 comprehensive and quantitative data provides a foundation for future studies to

42 understand the functional roles and biological significance of the polyploidy of insect

43 bacteriocytes. 


\section{$44 \quad$ Introduction}

45 Endopolyploidy or somatic polyploidy is generated through endoreduplication cycles, in

46 which the nuclear genome is repeatedly replicated without mitotic cell division ${ }^{[1-4]}$.

47 Polyploid cells are typically observed in tissues with high metabolic demand and are

48 considered not only to play essential roles in normal development but also to influence

49 ecologically important traits, such as body or organ size, growth rate, and nutrient

50 storage $^{[5,6]}$. Polyploidization is often attributed to increasing cellular size, metabolic rate,

51 and gene expression levels owing to the increasing availability of DNA templates for

52 transcription; these ideas have been supported by experiments in model organisms ${ }^{[3,7,8]}$.

53 Nevertheless, relatively few empirical studies have focused on endopolyploidy in

54 evolutionary and ecological contexts ${ }^{[6]}$.

55 Many insects, because of their unbalanced diet, live in symbiotic associations

56 with microorganisms, which can provide host insects with nutrients that cannot be

57 synthesized by insects or obtained from their diets ${ }^{[9-11]}$. Such endosymbiotic

58 microorganisms are frequently harbored in insect-specific cells or tissues

59 (endosymbiosis; ${ }^{[9,12-14]}$ ). So far, many researchers have pointed out that symbiotic host

60 cells (mycetocytes or bacteriocytes) have large nuclei and thus, would be polyploid in

61 various insect species ${ }^{[11-14]}$. Considering the well-known effects of polyploidy such as

62 cell enlargement and upregulation of gene expression, we can predict that

63 polyploidization of symbiotic host cells may have critical roles in endosymbiosis

64 between insects and microorganisms; however, very few studies have quantified the

65 ploidy levels of symbiotic host cells in insects. Exceptionally, Nakabachi et al. (2010)

66 revealed that in psyllid insects, Pachypsylla venusta (Osten-Sacken), symbiotic host cells

67 were 16-ploid in both adult males and females ${ }^{[15]}$. There are other reports on the ploidy 
68 levels of symbiotic host cells, but they are incomplete ${ }^{[16-18]}$.

69 Aphids (Hemiptera: Aphididae) have evolved symbiotic relationships with the

70 gamma-proteobacterium Buchnera aphidicola, which supplies the host with vitamins and

71 essential amino acids that aphids cannot synthesize or derive insufficiently from their diet,

72 the plant phloem sap ${ }^{[10,19,20]}$. B. aphidicola lives within large aphid cells, called

73 "bacteriocytes." The cells and another type of cells (small and flattened cells, called

74 "sheath cells") are grouped into organ-like structures, referred to as "bacteriomes"

75 (Figure 1a, b, ${ }^{[21]}$ ). Bacteriocytes were long thought to be polyploid because of their large

76 cellular and nuclear sizes (ca. 100 and $20 \mu \mathrm{m}$ in diameter, respectively) ${ }^{[12,13,22]}$. Moreover,

77 aphid bacteriocytes should be highly metabolically active, because they provide $B$.

78 aphidicola with a large amount of essential amino acids and other metabolites that the

79 symbiont can no longer produce, owing to the massive gene losses ${ }^{[23-25]}$. Therefore,

80 polyploidy may be a key element in the maintenance of the symbiotic system, as has been

81 shown in between leguminous plants and rhizobium bacteria ${ }^{[26-28]}$; however, information

82 about the ploidy levels of aphid bacteriocytes remains scarce.

83 Pea-aphid, Acyrthosiphon pisum (Harris), is one of the best-studied aphid species

84 in terms of life history (Figure 2, ${ }^{[29,30]}$ ), polymorphism (Figure S1, ${ }^{[30-32]}$ ), embryonic

85 development $^{[33-35]}$, nutritional symbiosis ${ }^{[23-25,}{ }^{36-38]}$, and genomics ${ }^{[39-41]}$. Detailed

86 descriptions have focused on bacteriocyte development during aphid embryogenesis ${ }^{[21}$,

$87^{22]}$, and it has been revealed that the number and volume of pea-aphid bacteriocytes

88 increase during post-embryonic development $\left({ }^{[38,42]}\right.$ but see $\left.{ }^{[43,44]}\right)$. These observations

89 imply that aphid bacteriocytes are already polyploid at the end of embryogenesis and

90 become hyper polyploid during post-embryonic development. However, no quantitative

91 data in this aspect have been reported. It should also be noted that most of the previous 
92 studies on aphid bacteriocytes characterized only viviparous insects, excluding other

93 morphs (e.g., oviparous females and males) - presumably because of the ease of rearing

94 viviparous insects in the laboratory (Figure S1).

95 In this study, we investigated the pattern of polyploidization and the cellular

96 features of pea-aphid bacteriocytes. We first observed the cytological features, such as

97 cell size and nucleolar number/size of bacteriocytes from adults of viviparous/oviparous

98 females and males, and other developmental stages of viviparous insects. Then, using

99 image-based fluorometry established in the present study, we determined the ploidy

100 levels of bacteriocytes and compared these levels among morphs (adult

101 viviparous/oviparous females and males). We also performed ploidy analysis on the cells

102 at each stage of post-embryonic development (from first-instar nymphs to senescent

103 adults in viviparous insects). Finally, based on our observation of the cytological features

104 of bacteriocytes, we discussed the potential effects of bacteriocyte polyploidy on the 105 aphid/Buchnera intracellular symbiosis.

107 Results

108 General observation and methods for ploidy analysis on aphid bacteriome cells

109 Consistent with previous observations ${ }^{[9,21,22,40]}$, the bacteriome of viviparous aphids

110 consisted of two types of cells: bacteriocytes and sheath cells (Figure 3). Bacteriocytes

111 contained Buchnera cells and were much larger than sheath cells. Sheath cells exhibited a

112 flattened morphology and surrounded the bacteriocytes. Both cell types possessed a

113 single nucleus. Bacteriocytes had a single prominent nucleolus, which was not stained

114 using DAPI, but using "Nucleolus Bright Red" staining (Figure 3). Most sheath cells also

115 had a single nucleolus, yet a small number had two. "Nucleolus Bright Red" also stained 
the peripheral region of Buchnera, probably because of the richness of RNA around

117 Buchnera cells.

118 To determine the most suitable methods for ploidy analysis of aphid bacteriocytes,

119 three types of methods, flow cytometry, Feulgen densitometry, and fluorometry were

120 compared. First, flow cytometry successfully detected the nuclei of bacteriome cells and

121 heads, and distinct peaks were present (Figure S2). There were several peaks, which can

122 be categorized as ploidy classes based on head peaks, assuming that the smallest peaks

123 correspond to a diploid population. We recognized peaks up to 256C (256-ploidy) cells

124 but could not distinguish cell types (i.e., bacteriocytes or sheath cells) in this method due

125 to a lack of cytological information. Note that " $\mathrm{C}$ " means haploid genome size, for

126 example, $2 \mathrm{C}=$ diploid and $8 \mathrm{C}=$ octoploid. Second, Feulgen densitometry also showed

127 several ploidy levels of up to $128 \mathrm{C}$ (Figure S3) in bacteriocytes. Sheath cells mainly

128 consisted of $16-32 \mathrm{C}$ cells. However, we found that many cells were lost during the

129 experimental procedures because the number of observed nuclei was too small.

130 We found the third method, image-based fluorometry for isolated nuclei, the best

131 for quantitative ploidy analysis of aphid bacteriocytes (Figure 4). Fluorometry showed

132 distinct peaks of integrated fluorescence intensity, and they could be categorized as each

133 ploidy class based on the intensity of the smallest peak in head cells (diploid population).

134 The results were consistent with other methods; ploidy levels were 32C-256C in

135 bacteriocytes and $16 \mathrm{C}-32 \mathrm{C}$ in sheath cells. In this analysis, the nucleolus size was used to

136 discriminate between cell types. During cytological observation, we obtained the size

137 distribution of the nucleolus, and it was revealed that the nucleolus of bacteriocytes was

138 always larger than that of sheath cells (Figure S4). Based on the results, we determined

139 the threshold of the size of the nucleolus. More specifically, in viviparous females, nuclei 
that have nucleoli larger than $20 \mu \mathrm{m}^{2}$ were categorized into bacteriocytes. Note that the

141 peaks of sheath cells were not distinct or reliable for categorizing their ploidy class;

therefore, we showed results focusing on bacteriocytes in the following sections.

143

\section{Cellular features of bacteriome cells in viviparous and oviparous females, and males}

145 The cellular features were generally consistent among adults of three morphs, viviparous 146 and oviparous females, and males (Figure 3). Buchnera-absence zones in the cytoplasm

147 of bacteriocytes, which are considered to be degeneration of Buchnera ${ }^{[45]}$, and 148 bacteriocytes degeneration ${ }^{[46]}$ were both observed more frequently in male bacteriocytes 149 than in females (Figure 3). The cell size of bacteriocytes was significantly different 150 among morphs (LM with type II test, $F=286.15, d f=2, p<0.001$, Figure S5).

151 Viviparous females had significantly larger bacteriocytes [449847.05 \pm 21583.0 (mean \pm $\left.152 \mathrm{SEM}) \mu \mathrm{m}^{3}, n=22\right]$ than other types of aphids (oviparous females, $298989.9 \pm 16196.6$ $153 \mu \mathrm{m}^{3}, n=24$, and males, $29020.35 \pm 3001.6 \mu \mathrm{m}^{3}, n=37$ ) (Tukey's test, $p<0.05$, Figure

154 S5). The size of nucleoli was significantly different between bacteriocytes and sheath 155 cells, regardless of aphid morphs (LMM with type II test; viviparous females, $\chi^{2}=618.4$, $d f=1, p<0.001$, oviparous females, $\chi^{2}=1,430.4, d f=1, p<0.001$, males, $\chi^{2}=261.37, d f$

$157=1, p<0.001$, Figure S3). There was no overlap in the nucleolus size between cell types 158 (Figure S4). Based on these data, we determined the threshold of the size of the nucleolus 159 to discriminate between bacteriocytes and sheath cells. Specifically, in viviparous and 160 oviparous females, and males, nuclei that have nucleoli larger than $20 \mu \mathrm{m}^{2}, 20 \mu \mathrm{m}^{2}, 8 \mu \mathrm{m}^{2}$, 161 were categorized into bacteriocytes, respectively. 
164 Ploidy analysis of the adult bacteriocytes revealed that the cells were highly polyploid

165 (from $32 \mathrm{C}$ to $256 \mathrm{C}$ ) in all phenotypes (Figure 5). We found variation in the level of

166 ploidy; bacteriocytes of viviparous females, oviparous females, and males mainly

167 consisted of $64-128 \mathrm{C}$ (45\% for each), 64C (70\%), and 32-64C (30\% and 47\%),

168 respectively. There were significant differences in the degree of polyploidy (median

169 ploidy level) in bacteriocytes among the three aphid phenotypes (Brunner-Munzel test

170 with Bonferroni adjustment; viviparous females vs. oviparous females, $p<0.05$;

171 viviparous females vs. males, $p<0.05$; oviparous females vs. males, $p<0.05$; Figure 5).

173 Fecundity and longevity of viviparous and oviparous females

174 Viviparous females in this strain laid $95.25 \pm 24.75$ (mean $\pm \mathrm{SD}, n=12$ ) nymphs during

175 their lifetime, while oviparous females oviposited $28.83 \pm 6.52(n=12)$ eggs (Figure S6).

176 The total number of nymphs laid by viviparous females was significantly higher than that 177 of eggs oviposited by oviparous females (GLMM with type II test, $\chi^{2}=449.74, d f=1, p<$

178 0.001). Viviparous females lived longer [44.33 \pm 4.38 (mean \pm SEM) days] than

179 oviparous ones (26.08 \pm 2.31 days $)$, yet there was no interaction between female types

180 and their lifetime (GLMM, with type II test; female type, $\chi^{2}=118.13, d f=1, p<0.001$,

181 lifetime, $\chi^{2}=69.32, \mathrm{df}=1, p<0.001$, and the interaction $\chi^{2}=0.74, d f=1, p=0.39$ ).

182 Viviparous females started reproducing from days 2-3 and the rate of larviposition peaked

183 during days 3-20 but slowed down during days 21-28. They lived at most 50-55 days,

184 although most of them stopped the larviposition after day 30. In oviparous females, first

185 oviposition and mating with males were observed on days 3-4. They actively laid eggs

186 until day 14, but their death was observed almost simultaneously (Figure. S6). 
189 At $16{ }^{\circ} \mathrm{C}$, viviparous (and apterous) aphids reached adult stage approximately 14 days 190 after birth [13.73 \pm 0.32 (mean $\pm \mathrm{SEM}$ ), $n=16$, Figure 6a]. In particular, N1, N2, N3, and $\mathrm{N} 4$ periods lasted for $3.2 \pm 0.11,3.0 \pm 0.09,3.3 \pm 0.12$, and $4.2 \pm 0.14$ days (mean $\pm \mathrm{SEM}$, $n=16$, Figure 6a), respectively. Adult aphids started reproducing 2 or 3 days after eclosion (molt for an adult) and continued larviposition for approximately 4 weeks (Figure S6). Based on these data, A7 aphids (7 days after eclosion) could be categorized as actively reproducing individuals. A21 aphids (21 days after eclosion) were categorized as senescent individuals, although they continuously produced offspring. During the nymphal stages of viviparous aphids, the morphology of bacteriome cells was generally consistent; all bacteriocytes and most sheath cells were uninuclear (Figure 6b), but very

199 few of the latter cells had several small nuclei. Notably, there were drastic morphological changes in adult stages; bacteriocyte and sheath cell nuclei of A21 individuals were irregularly shaped in comparison with those of young (A0) and reproducing (A7) individuals. Furthermore, in A21, we frequently observed bacteriocytes in which the signals of DAPI and nucleolus bright red signals on Buchnera were weak (Figure 6b). These changes were consistent with symptoms of Buchnera degeneration and cell

205 senescence, which have been previously reported ${ }^{[45,46]}$. Developmental stages had a 206 significant effect on bacteriocyte size (LMM with type II test, $\chi^{2}=338.73, d f=6, p<$ 207 0.001). During post-embryonic development, the size of bacteriocytes consistently 208 increased (Tukey's test: $\mathrm{N} 1=\mathrm{N} 2=\mathrm{N} 3<\mathrm{N} 4<\mathrm{A} 0=\mathrm{A} 7<\mathrm{A} 21, p<0.05$, Figure S7). The 209 size of nucleoli was significantly different between bacteriocytes and sheath cells, 210 regardless of the post-embryonic developmental stages (LMM with type II test; $\mathrm{N} 1, \chi^{2}=$ 211 891.82, $d f=1, p<0.001, \mathrm{~N} 2, \chi^{2}=294.04, d f=1, p<0.001, \mathrm{~N} 3, \chi^{2}=842.31, d f=1, p<$ 
$2120.001, \mathrm{~N} 4, \chi^{2}=817.18, d f=1, p<0.001$, old adults, $\chi^{2}=1,405.6, d f=1, p<0.001$, Figure

213 S8). There was no overlap in the nucleolus size between cell types (Figure S8). Based on

214 these data and the data from young adults, we determined the threshold of the size of the

215 nucleolus for ploidy analysis (in N1 and N2, $10 \mu \mathrm{m}^{2}$, and later stages, $25 \mu \mathrm{m}^{2}$ ).

Ploidy dynamics of aphid bacteriocytes along with post-embryonic development

218 During post-embryonic development of viviparous females, the ploidy level of 219 bacteriocytes gradually increased; bacteriocytes were 16-32C at the time of birth (N1) 220 and reached the highest ploidy level in actively reproducing adults (A7, 128-256C) 221 (Figure 7). All stages of viviparous females except senescence stage A21 showed 222 significant differences in ploidy levels (Brunner-Munzel test with Bonferroni adjustment, $223 \mathrm{~N} 1<\mathrm{N} 2<\mathrm{N} 3<\mathrm{N} 4<\mathrm{A} 0<\mathrm{A} 21<\mathrm{A} 7, p<0.05$, Figure 7). The highest dominant ploidy 224 class was observed in A7 aphids (256C, 43\%) (Figure 7). A similar pattern was observed 225 in oviparous aphids (Figure S9), and the highest dominant ploidy was also observed in A7 individuals (but 128C, 47\%).

Relationship between the size of the nucleolus and ploidy levels in aphid bacteriocytes

There were significant effects of ploidy class on the size of the nucleolus in adult

230 bacteriocytes of each morph (LM with type II test; viviparous females, $F=62.94, d f=2$, $p<0.001$, oviparous females, $F=23.97, d f=2, p<0.001$; males, $F=6.44, d f=3, p<$ 0.001 , Figure $8 \mathrm{a})$. Note that $16 \mathrm{C}$ and $256 \mathrm{C}$ viviparous bacteriocytes were excluded from the analysis due to their small number. Similarly, 16C and 8C cells of females and males, respectively, were excluded from the analysis. In viviparous females, the size of the nucleolus consistently increased from 32C to $128 \mathrm{C}$ (Tukey's test, $p<0.001$ ). In oviparous 
females, 128C cells had larger nucleoli than 32C and 64C cells $(p<0.001$ each), yet the difference between $32 \mathrm{C}$ and $64 \mathrm{C}$ cells was marginally non-significant $(p=0.06)$. In males,

238 the size of the nucleolus of $128 \mathrm{C}$ cells was significantly larger than that of $16 \mathrm{C}$ and $32 \mathrm{C}$

239 cells $(p<0.001$ each), but we did not find any significant difference among other

240 comparisons $(16 \mathrm{C}$ vs. $32 \mathrm{C}, p=0.71,16 \mathrm{C}$ vs. $64 \mathrm{C}, p=0.10,32 \mathrm{C}$ vs $64 \mathrm{C}, p=0.08,64 \mathrm{C}$ vs

241 128C, $p=0.18$ ) (Figure 8a). A significant effect of ploidy class on the nucleolus size was

242 also detected in the data from each developmental stage of viviparous aphids (LMM with

243 type II test; $\chi^{2}=788.83, d f=5, p<0.001$, Figure $8 b$ ). Note that $4 \mathrm{C}$ and $512 \mathrm{C}$

244 bacteriocytes were excluded from the analysis because of the small number of 245 observations. The size of the nucleolus consistently increased from 8C to 256C (Tukey's 246 test, $p<0.05$, Figure 8b).

\section{Discussion}

249 This study presented quantitative data on ploidy levels and ploidy dynamics in the 250 bacteriocytes, which are pivotal cells in aphid/Buchnera endosymbiosis. The method 251 developed for ploidy analysis of aphid bacteriocytes in this study (Figure 4) revealed the 252 hyper polyploidy of the bacteriocytes ranging from 16- to 256-ploidy throughout the 253 lifecycle. We also found significant differences in the ploidy levels among morphs in 254 adult stages (viviparous females > oviparous females > males, Figure 5) and 255 developmental stages in viviparous females (reproducing adults > senescent adults > 256 pre-reproducing adults $>$ nymphs, Figure 7). Considering that viviparous adults exhibited 257 a high rate of reproduction, which was at a maximum in the first three weeks (Figure S6), 258 more metabolically active (actively reproducing) individuals may show higher 259 polyploidy in their bacteriocytes. We observed a similar pattern of bacteriocyte 
260 polyploidy in oviparous aphids (Figure S9), yet the highest ploidy level was lower than

261 viviparous females. These results provide fundamental information to understand the

262 functional significance of polyploidy in aphid bacteriocytes.

263 Our findings in this study raise the possibility that bacteriocyte polyploidy can

264 enhance nutritional symbiosis between aphids and B. aphidicola, wherein both supply

265 each other with nutrients that they cannot synthesize on their own ${ }^{[10,19,20]}$. Specifically,

266 we predict that genes involved in amino acid metabolism, related to transport, and for

267 symbiont regulation (e.g., lysozymes or cysteine-rich secreted proteins targeting bacteria),

268 which have been reported to be highly expressed in the aphid bacteriomes ${ }^{[24,25,38,40]}$, may

269 be upregulated in a ploidy-dependent manner ${ }^{[6,7,47]}$. On the other hand, it is commonly

270 known that cell volumes change depending on ploidy levels ${ }^{[6,48]}$. In fact, our data

271 suggested a positive correlation between bacteriocyte volume and ploidy level in the

272 aphid bacteriocytes (Figure S5 and S7). Bacteriocyte enlargement may simply increase

273 the number of $B$. aphidicola that can be harbored, which should lead to enhanced

274 nutritional symbiosis. In order to examine the effect of polyploidization on the

275 aphid/Buchnera symbiosis, an integrated approach including gene expression analysis on

276 a per-nucleus basis, and monitoring cell phenotypes such as ploidy-level and cell/nuclear

277 size is required.

278 In this study, we also found positive correlations between the ploidy class of

279 bacteriocytes and the size of their nucleoli, regardless of the morphs and developmental

280 stage (Figure 8). The main function of the nucleolus is ribosomal biogenesis, and the size

281 and morphology of nucleoli are linked to nucleolar activity, such as transcription and

282 ribosomal RNA production rates ${ }^{[49-51]}$. In plants, there is evidence that more polyploid

283 nuclei not only exhibit larger nucleolar size but also exhibit increased transcription of 
rRNA and mRNA; a positive correlation between DNA content and transcriptional

285 activity has been identified in the polyploid tomato fruit pericarp ${ }^{[8]}$. Our data are

286 consistent with the hypothesis that aphid bacteriocytes with higher ploidy levels produce

287 more ribosomal RNA, leading to higher metabolic activity; a direct relationship between

288 ploidy levels and nucleolar activity needs to be examined in future studies.

Aphid bacteriocytes have long been considered to be polyploid [Myzus persicae (Sulzer) $^{[18]}$, Pemphigus spyrothecae Passerini ${ }^{[22]}$, and Cinara species $\left.{ }^{[52]}\right]$. Furthermore, it has been concluded that bacteriocytes are polyploid in many other insects, such as

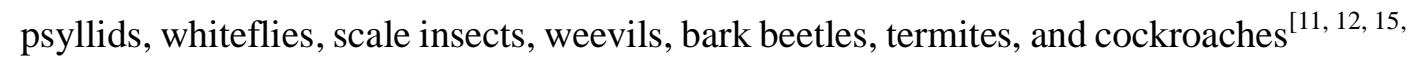
${ }^{53-56]}$, although quantitative data were lacking, except for psyllids ${ }^{[15]}$. In this study, by comprehensively describing the patterns of polyploidization, we demonstrated, for the first time, that high metabolic demand such as active reproduction is associated with higher polyploidy levels in aphid bacteriocytes. It would be valuable to investigate this relationship in intracellular symbiosis in various insect species. Accumulating information on bacteriocyte polyploidy will help us gain a better understanding of the maintenance and evolution of mutual relationships between host and symbionts because polyploidization in the symbiotic host cells is a common rule in insect-microorganism intracellular symbioses ${ }^{[12,13,57]}$. and found an image-based fluorometry the best for the analysis of aphid bacteriomes (Figure 4), because it could distinguish between cell types (e.g., bacteriocytes and sheath cells) by the size of nucleolus, unlike flow cytometry (Figure S2). In addition, it was timesaving compared with Feulgen densitometry (Figure S3). Our results from 
308 viviparous aphids, although peaks in the histogram were not clear (Figure 4); therefore,

309 nuclei exhibiting more than $32 \mathrm{C}$ can be reasonably assumed to be bacteriocytes. These

310 approach, the combination of several methods such as the fluorometry and flow

311 cytometry would be applicable to other symbiotic systems of insects with

312 microorganisms, wherein the bacteriome frequently contains several types of cells (e.g.,

313 primary or secondary bacteriocytes, and sheath cells $)^{[13,14,21]}$.

314 In conclusion, we comprehensively described the patterns of polyploidization in

315 aphid bacteriocytes, which has long been assumed to be polyploid, yet there have been no

316 quantitative studies ${ }^{[9,10,14]}$. Based on the patterns and cytological features observed in

317 this study, we suggest that hyper polyploidy may enhance gene expression levels and

318 increase cell size, contributing to the nutritional symbiosis with the bacterial symbiont $B$.

319 aphidicola. This study provides a foundation for further molecular-level analysis of the

320 functions and underlying mechanisms of polyploidy in insect symbiotic host cells.

322 Material and methods

323 Aphids

324 In this study, we used a long-established parthenogenetic clone of the pea-aphid, A. pisum, 325 ApL strain, which was originally collected in Sapporo, Hokkaido, Japan (referred to as 326 Sap05Ms2 in ${ }^{[58]}$ ). We confirmed that this strain only harbors the primary endosymbiont $B$. 327 aphidicola by diagnostic PCR, as described in a previous study ${ }^{[59]}$. Viviparous insects 328 were maintained on young, broad bean plants (Vicia faba L.) in a $16{ }^{\circ} \mathrm{C}$ incubator, with a 329 photoperiod of $16 \mathrm{~h}$ light:8 h dark (long-day conditions). Sexual morphs (oviparous 330 females and males) were induced by short-day conditions (e.g., $8 \mathrm{~h}$ light:16 h dark) 331 (Figure 2, S1, modified from ${ }^{[58,60,61]}$ ). Viviparous females were randomly selected from 
the synchronized source populations and reared on young broad bean plants at $16{ }^{\circ} \mathrm{C}$

$334 \mathrm{~S} 1$ ) were then transferred onto the leaves of the bean plants in a $15{ }^{\circ} \mathrm{C}$ incubator with a offspring, and all viviparous individuals were apterous. To reveal the fecundity and longevity of both viviparous and oviparous aphids, female aphids were reared separately and observed daily (see supplementary information "SI Methods").

\section{Size and morphology of aphid bacteriome cells}

345 Aphid bacteriomes consist of two types of cells: bacteriocytes containing Buchnera cells

346 in their cytoplasm and sheath cells without them (Figure $1 b,{ }^{[9,21,40]}$ ). To gain more

347 detailed cellular features of aphid bacteriocytes, we performed a morphological analysis

348 of bacteriomes using a confocal laser-scanning microscope (CLSM; FV1000, Olympus,

349 Japan) on three adult morphs (viviparous/oviparous females and males). These adults

350 were within 5 days of eclosion. We also observed the bacteriome at each stage of

351 viviparous females [nymphs N1 (first-instar nymph), N2 (second-instar nymph), N3

352 (third-instar nymph), and N4 (fourth-instar nymph), and young adults (3-5 days after

353 eclosion), and old adults (approximately 21 days after eclosion)]. Each stage of

354 viviparous females was used on the day of molting, but teneral insects were not used).

355 Aphid bacteriomes were dissected in phosphate-buffered saline (PBS: $33 \mathrm{mM} 143$ 
$356 \mathrm{KH}_{2} \mathrm{PO}_{4}, 33 \mathrm{mM} \mathrm{Na} \mathrm{HPO}_{4}, \mathrm{pH}$ 6.8) under a stereomicroscope (SZ61, Olympus, Japan),

357 with fine forceps, and their bacteriome cells (bacteriocytes and sheath cells) were

358 surgically isolated from the aphid abdomen. The cells were fixed with $4 \%$

359 paraformaldehyde in PBS for $30 \mathrm{~min}$. Fixed bacteriome cells were washed three times in

$360 \quad 0.3 \%$ Triton X-100 in PBS (PBS-T) for 15 min for permeabilization. The cells were then

361 stained with 4,6-diamidino-2-phenylindole (DAPI) (1 $\mu \mathrm{g} / \mathrm{mL}$; Dojindo, Japan) for the

362 nuclei and Alexa Fluor ${ }^{\mathrm{TM}} 488$ phalloidin (66 nM; Thermo Fisher Scientific, USA) for the

363 cytoskeleton (F-actin), respectively. The nucleolus, which is the site of both ribosomal

364 RNA (rRNA) synthesis and the assembly of ribosomal subunits ${ }^{[49]}$, was visualized using

365 Nucleolus Bright Red (1 mM; Dojindo, Japan). Nucleolus Bright Red dyes are small

366 molecules that electrostatically bind to RNA in the nucleolus to emit fluorescence. After 1

$367 \mathrm{~h}$ at room temperature (from 20 to $25^{\circ} \mathrm{C}$ ), the cells were washed three times with PBS-T

368 for $15 \mathrm{~min}$ and mounted with VECTASHIELD antifade mounting medium (Vector

369 Laboratories, USA). The morphology of the bacteriocytes and sheath cells was visualized

370 using fluorescent staining and differential interference contrast microscopy. The captured

371 images were processed using the image analysis software ImageJ (NIH,

372 http://rsb.info.nih.gov/ij/). The diameter of each bacteriocyte (D) was measured at its

373 widest point. The approximate bacteriocyte volume $(\mathrm{V})$ was calculated using the standard

374 formula: $V=\left(\frac{\pi}{6}\right) D^{3}$. The nucleolus size (area) of both the bacteriocytes and sheath cells

375 was also recorded.

377 Establishment of the method for ploidy analysis on aphid bacteriocytes

378 To establish a method for ploidy analysis of aphid bacteriocytes, we used three methods:

379 flow cytometry, Feulgen densitometry, and fluorometry. Young adult viviparous aphids 
380 (3-5 days after eclosion) or late instar (third-fourth instar) of nymphs were used. In all analyses, not only bacteriome cells but also head cells were used as diploid controls, which were confirmed as diploid by preliminary analysis of sperm cells (haploid). We first performed flow cytometry, which is an efficient and commonly used method for nuclear DNA-content analysis ${ }^{[62,63]}$. For this analysis, bacteriome cells dissected from five aphids were suspended and repeatedly pipetted in $250 \mu \mathrm{L}$ of trypsin buffer $(0.11 \%$ Nonidet P40, $0.1 \%$ sodium citrate, $0.05 \%$ spermine tetrahydrochloride, $0.01 \%$ Tris base, and $0.003 \%$ trypsin in distilled water). Heads were ground with tight-fitting pestles in the trypsin buffer. After incubation at room temperature (from 20 to $25^{\circ} \mathrm{C}$ ) for $10 \mathrm{~min}, 5 \mu \mathrm{L}$ of trypsin inhibitor solution (trypsin inhibitor, from soybean, $25 \mathrm{mg} / \mathrm{mL}$ ) and $1 \mu \mathrm{L}$ of RNase A $(100 \mathrm{mg} / \mathrm{mL})$ were added. After the mixture was incubated at room temperature (from 20 to $25^{\circ} \mathrm{C}$ ) for $10 \mathrm{~min}, 250 \mu \mathrm{L}$ of dilution buffer $(0.11 \%$ Nonidet $\mathrm{P} 40,0.1 \%$ sodium citrate, $0.17 \%$ spermine tetrahydrochloride, and $0.01 \%$ Tris base in distilled water) was added, and the mixture was filtered through a $48 \mu \mathrm{m}$ nylon mesh. Isolated nuclei were stained with DAPI $(1 \mu \mathrm{g} / \mathrm{mL})$. The filtered mixture was incubated at room temperature for at least $10 \mathrm{~min}$ and stored on ice until use. Stained nuclei were analyzed for DNA-DAPI fluorescence using a Cell Sorter SH800 (SONY, Japan) at an excitation wavelength of $405 \mathrm{~nm}$. Each experiment was performed in triplicates. bacteriome cells ${ }^{[15]}$. This analysis was performed according to the protocol of Hardie et al. $(2002)^{[64]}$. Briefly, the bacteriome cells and heads were dissected from an aphid and then smeared on glass slides. The smears were fixed in MFA (methanol, formalin, acetic acid $=85: 10: 5 \mathrm{v} / \mathrm{v}$ ) for $24 \mathrm{~h}$, hydrolyzed in $5.0 \mathrm{~N} \mathrm{HCl}$ for $2 \mathrm{~h}$, and stained with Schiff 
reagent for $2 \mathrm{~h}$. Images of stained nuclei were captured with a BX-61 microscope

405 (Olympus, Japan) and a DS-Fi1 CCD camera (Nikon, Japan). All the steps were performed at room temperature (from 20 to $25^{\circ} \mathrm{C}$ ). Using ImageJ, the green channel was extracted, and the integrated optical density (IOD) of the Feulgen stain in the nuclei was measured. Background signal intensity was measured in an area adjacent to each nucleus and deduced from the nuclear IOD. Each experiment was performed in triplicates. In this analysis, the nuclei of bacteriome cells were not isolated; therefore, we can categorize cell types based on their cytoplasmic status [Buchnera presence (bacteriocyte) or absence 412 (sheath cells)].

Third, image-based fluorometry of the isolated nuclei was conducted. Bacteriome cells were dissected from three individuals in PBS, and the PBS droplets containing the cells were transferred onto glass slides by careful pipetting. Nuclear isolation buffer $(10 \mu \mathrm{L})$, identical to "dilution buffer," was added to the cells on the glass slide. The nuclei of these cells were isolated by agitation using fine needles (insect pins, Shiga Konchu Fukyusha, Japan) in the droplets. This step was completed using an SZ61 stereomicroscope. After drying the nuclei on the glass slide, they were fixed in MFA for $30 \mathrm{~min}$ at room temperature (from 20 to $25{ }^{\circ} \mathrm{C}$ ). The slides were washed thrice with distilled water. Nuclei were stained with DAPI solution $(1 \mu \mathrm{g} / \mathrm{mL}$ DAPI and $2 \mathrm{mg} / \mathrm{mL}$ RNase A) for $1 \mathrm{~h}$ at room temperature (from 20 to $25^{\circ} \mathrm{C}$ ). The slides were washed three times with distilled water and mounted with VECTASHIELD antifade mounting medium.

424 The same devices used for the Feulgen densitometry were used for image capturing.

425 Using ImageJ, the blue channel was extracted, and the integrated fluorescent intensity 426 (IFI), which is the integrated gray value in the region of interest, was measured for each 427 nucleus. The background signal intensity was measured in an area adjacent to each 
nucleus and deduced from nuclear IFI. The experiment was performed in duplicates. In this analysis, the nucleolus size (area) was also measured and compared with the data

430 from confocal microscopy to discriminate cell types (bacteriocytes and sheath cells).

Ploidy analysis for each morph, and each developmental stage of viviparous aphids

Bacteriome cells and heads were dissected in PBS and processed with the abovementioned "fluorometry" method. First, to assess the variation in the degree of polyploidy among morphs, young adult individuals (3-5 days after adult eclosion) of viviparous/oviparous females and males were used. Three individuals were pooled for each morph. Nucleolus sizes were recorded to discriminate cell types. Second, to elucidate the dynamics of polyploidization and post-embryonic development of aphids, bacteriocytes of viviparous aphids at different developmental stages were analyzed.

440 Specifically, the following stages were used: nymphs N1, N2, N3, and N4, and adults at 441 three distinct time points: A0 (0 days after eclosion) as pre-reproductive adults, A7 (7 days after eclosion) as actively reproducing adults, and A21 (21 days after eclosion) as senescent individuals. All viviparous individuals were apterous. Each stage of viviparous

444 females was used on the day of molting, but teneral insects were not used. To discriminate 445 cell types, the nucleolus size (area) was measured and compared with the data obtained 446 by confocal microscopy. Nucleolus sizes have also been used as indicators of the 447 translation activity of cells ${ }^{[8,49]}$. Three individuals were used in each stage. Additionally, 448 each developmental stage of oviparous females (nymphs N1, N2, N3, and N4, and A0 and 449 A7 adults) was also analyzed. For discrimination of cell types in oviparous females, data 450 from viviparous females were used, because we preliminarily confirmed that the size of 451 the nucleolus of bacteriocytes in oviparous females was not significantly different from 
that in viviparous females. Three individuals were included in each stage.

\section{$454 \quad$ Statistical analysis}

455 To compare the size of bacteriocytes among aphid morphs (young adults of viviparous

456 females, oviparous females, and males), we used a linear model (LM), followed by

457 Tukey's post hoc test. In this analysis, morphs were treated as fixed effects. For analysis

458 of cell size among the developmental stages of viviparous females, we used linear mixed

459 models (LMM), followed by Tukey's post hoc test. In the analysis, developmental stages

460 and individuals were included as fixed and random effects, respectively. For pairwise

461 comparisons of ploidy levels of bacteriocytes among morphs and developmental stages

462 of viviparous/oviparous females, we used the Brunner-Munzel test, which is a

463 non-parametric test that adjusts for unequal variances. Significant $p$-values were adjusted

464 using Bonferroni's correction. To compare the size of the nucleolus in bacteriocytes,

465 which was recorded during fluorometry, among ploidy classes, we used LMs and LMMs,

466 followed by Tukey's HSD post hoc test. In these analyses, ploidy classes were treated as

467 factorial fixed effects. All analyses were performed for each morph. In the analysis of

468 developmental stages, data from each stage were pooled, and individuals were included

469 as a random effect. All analyses were conducted using the "car", "emmeans", "lawstat",

470 "Ime4", and "multcomp" packages in R software v4.1.1 (https://www.r-project.org/). 


\section{$471 \quad$ References}

472 1. Nagl, W. DNA endoreduplication and polyteny understood as evolutionary strategies. Nature 261,

473 614-615 (1976). DOI: $\underline{10.1038 / 261614 a 0}$, Pubmed: $\underline{934306}$.

474 2. Edgar, B. A. \& Orr $\square$ Weaver, T. L. Endoreplication cell cycles: more for less. Cell 105, 297-306

475 (2001). DOI: 10.1016/S0092-8674(01)00334-8, Pubmed: 11348589.

476 3. Edgar, B. A., Zielke, N. \& Gutierrez, C. Endocycles: A recurrent evolutionary innovation for 477 post $\square$ mitotic cell growth. Nat. Rev. Mol. Cell Biol. 15, 197-210 (2014). DOI: 10.1038/nrm3756, $478 \quad$ Pubmed: 24556841.

479 4. Shu, Z., Row, S. \& Deng, W. M. Endoreplication: the good, the bad, and the ugly. Trends Cell 480 Biol. 28, 465-474 (2018). DOI: 10.1016/j.tcb.2018.02.006, Pubmed: 29567370.

481 5. Lee, H. O., Davidson, J. M. \& Duronio, R. J. Endoreplication: polyploidy with purpose. Genes 482 Dev. 23, 2461-2477 (2009). DOI: $\underline{\text { 10.1101/gad.1829209, Pubmed: } 19884253 .}$

483 6. Neiman, M., Beaton, M. J., Hessen, D. O., Jeyasingh, P. D. \& Weider, L. J. Endopolyploidy as a 484 potential driver of animal ecology and evolution. Biol. Rev. Camb. Philos. Soc. 92, 234-247 (2017). DOI: 10.1111/brv.12226, Pubmed: $\underline{26467853}$.

7. Galitski, T., Saldanha, A. J., Styles, C. A., Lander, E. S. \& Fink, G. R. Ploidy regulation of gene expression. Science 285, 251-254 (1999). DOI: 10.1126/science.285.5425.251, Pubmed: 10398601.

8. Bourdon, M. et al. Evidence for karyoplasmic homeostasis during endoreduplication and a $490 \quad$ ploidy-dependent increase in gene transcription during tomato fruit growth. Development 139, 3817-3826 (2012). DOI: 10.1242/dev.084053, Pubmed: 22991446. York, 1965). 
bacteria Buchnera. Annu. Rev. Entomol. 43, 17-37 (1998). DOI: 10.1146/annurev.ento.43.1.17,

Pubmed: $\underline{15012383 .}$

11. Baumann, P., Moran, N. A., Baumann, L. \& Dworkin, M. Bacteriocyte-associated endosymbionts of insects in The Prokaryotes (ed. Dworkin, M., Falkow, S., Rosenberg, E., Schleifer, K. H. \& Stackebrandt, E.). DOI: 10.1007/0-387-30741-9_16 (Springer, New York, 2006).

12. Koch, A. Intracellular symbiosis in insects. Annu. Rev. Microbiol. 14, 121-140 (1960). DOI: 10.1146/annurev.mi.14.100160.001005, Pubmed: 13757312.

13. Douglas, A. E. Mycetocyte symbiosis in insects. Biol. Rev. Camb. Philos. Soc. 64, 409-434 (1989). DOI: 10.1111/j.1469-185X.1989.tb00682.x, Pubmed: 2696562.

14. Moran, N. A. \& Telang, A. Bacteriocyte-associated symbionts of insects. BioScience 48, 295-304 (1998). DOI: 10.2307/1313356.

15. Nakabachi, A., Koshikawa, S., Miura, T. \& Miyagishima, S. Genome size of Pachypsylla venusta (Hemiptera: Psyllidae) and the ploidy of its bacteriocyte, the symbiotic host cell that harbors intracellular mutualistic bacteria with the smallest cellular genome. Bull. Entomol. Res.

16. Brown, S. W. The Comstockiella system of chromosome behavior in the armored scale insects (Coccoïdea: Diaspididae). Chromosoma 14, 360-406 (1963). DOI: 10.1007/BF00326785.

18. Blackman, R. L. Reproduction, cytogenetics and development. Aphids: their Biology, Natural Enemies and control 2, 163-195 (1987). 
obligate bacterial symbiont. Cell. Mol. Life Sci. 68, 1297-1309 (2011). DOI: 10.1007/s00018-011-0645-2, Pubmed: 21390549.

20. Hansen, A. K., Pers, D. \& Russell, J. A. Symbiotic solutions to nitrogen limitation and amino acid imbalance in insect diets. Adv. Insect Physiol. 58, 161-205 (2020). DOI:

22. Braendle, C. et al. Developmental origin and evolution of bacteriocytes in the aphid-Buchnera 10.1016/bs.aiip.2020.03.001.

21. Koga, R., Meng, X. Y., Tsuchida, T. \& Fukatsu, T. Cellular mechanism for selective vertical transmission of an obligate insect symbiont at the bacteriocyte-embryo interface. Proc. Natl Acad. Sci. U. S. A. 109, E1230-E1237 (2012). DOI: 10.1073/pnas.1119212109, Pubmed: symbiosis. PLOS Biol. 1, e21 (2003). DOI: 10.1371/journal.pbio.0000021.

23. Shigenobu, S., Watanabe, H., Hattori, M., Sakaki, Y. \& Ishikawa, H. Genome sequence of the

25. Hansen, A. K. \& Moran, N. A. Aphid genome expression reveals host-symbiont cooperation in the production of amino acids. Proc. Natl Acad. Sci. U. S. A. 108, 2849-2854 (2011). DOI: 10.1073/pnas.1013465108, Pubmed: 21282658.

26. Kondorosi, E. \& Kondorosi, A. Endoreduplication and activation of the anaphase-promoting complex during symbiotic cell development. FEBS Lett. 567, 152-157 (2004). DOI: 10.1016/j.febslet.2004.04.075, Pubmed: 15165909.

27. Kondorosi, E., Mergaert, P. \& Kereszt, A. A paradigm for endosymbiotic life: cell differentiation 
of Rhizobium bacteria provoked by host plant factors. Annu. Rev. Microbiol. 67, 611-628 (2013).

DOI: $\underline{\text { 10.1146/annurev-micro-092412-155630, Pubmed: } 24024639 .}$.

28. Suzaki, T. et al. Endoreduplication-mediated initiation of symbiotic organ development in Lotus japonicus. Development 141, 2441-2445 (2014). DOI: 10.1242/dev.107946, Pubmed: 24850853.

29. Brisson, J. A. \& Davis, G. K. Pea aphid in Genome Mapping and Genomics in Arthropods (59-67) (Springer, Berlin, Heidelberg, 2008). through viviparity. Front. Physiol. 5, 1 (2014). DOI: 10.3389/fphys.2014.00001, Pubmed:

33. Miura, T. et al. A comparison of parthenogenetic and sexual embryogenesis of the pea aphid Acyrthosiphon pisum (Hemiptera: Aphidoidea). J. Exp. Zool. B Mol. Dev. Evol. 295, 59-81

34. Chang, C. C., Lee, W. C., Cook, C. E., Lin, G. W. \& Chang, T. Germ-plasm specification and germline development in the parthenogenetic pea aphid Acyrthosiphon pisum: Vasa and Nanos as markers. Int. J. Dev. Biol. 50, 413-421 (2006). DOI: 10.1387/ijdb.052100cc, Pubmed: 16525937.

35. Chung, C. Y., Cook, C. E., Lin, G. W., Huang, T. Y. \& Chang, C. C. Reliable protocols for whole $\square$ mount fluorescent in situ hybridization (FISH) in the pea aphid Acyrthosiphon pisum: A comprehensive survey and analysis. Insect Sci. 21, 265-277 (2014). DOI: 
36. Price, D. R. et al. Aphid amino acid transporter regulates glutamine supply to intracellular bacterial symbionts. Proc. Natl Acad. Sci. U. S. A. 111, 320-325 (2014). DOI: 10.1073/pnas.1306068111, Pubmed: 24367072.

37. Feng, H. et al. Trading amino acids at the aphid-Buchnera symbiotic interface. Proc. Natl Acad. Sci. U. S. A. 116, 16003-16011 (2019). DOI: 10.1073/pnas.1906223116, Pubmed: 31337682.

38. Pers, D. \& Hansen, A. K. The boom and bust of the aphid's essential amino acid metabolism across nymphal development. G3 (Bethesda) 11 (2021). DOI: 10.1093/g3journal/jkab115, Pubmed: $\underline{33831149}$.

39. International Aphid Genomics Consortium. Genome sequence of the pea aphid Acyrthosiphon

40. Shigenobu, S. \& Stern, D. L. Aphids evolved novel secreted proteins for symbiosis with bacterial endosymbiont. Proc. Biol. Sci. 280, 20121952 (2013). DOI: $\underline{10.1098 / \mathrm{rspb} .2012 .1952 .}$

41. Li, Y., Park, H., Smith, T. E. \& Moran, N. A. Gene family evolution in the pea aphid based on chromosome-level genome assembly. Mol. Biol. Evol. 36, $2143-2156$ (2019). DOI: 10.1093/molbev/msz138, Pubmed: 31173104.

42. Simonet, P. et al. Direct flow cytometry measurements reveal a fine-tuning of symbiotic cell dynamics according to the host developmental needs in aphid symbiosis. Sci. Rep. 6, 19967 (2016). DOI: 10.1038/srep19967, Pubmed: 26822159.

43. Douglas, A. E. \& Dixon, A. F. G. The mycetocyte symbiosis of aphids: variation with age and morph in virginoparae of Megoura viciae and Acyrthosiphon pisum. J. Insect Physiol. 33, 109-113 (1987). DOI: 10.1016/0022-1910(87)90082-5.

44. Douglas, A. E. \& Wilkinson, T. L. Host cell allometry and regulation of the symbiosis between 
pea aphids, Acyrthosiphon pisum, and bacteria, Buchnera. J. Insect Physiol. 44, 629-635 (1998).

DOI: 10.1016/s0022-1910(98)00030-4, Pubmed: 12769945.

45. Nishikori, K., Kubo, T. \& Morioka, M. Morph-dependent expression and subcellular localization of host serine carboxypeptidase in bacteriocytes of the pea aphid associated with degradation of the endosymbiotic bacterium Buchnera. Zoolog. Sci. 26, 415-420 (2009). DOI: 10.2108/zsj.26.415, Pubmed: 19583501.

46. Simonet, P. et al. Bacteriocyte cell death in the pea aphid/Buchnera symbiotic system. Proc. Natl Acad. Sci. U. S. A. 115, E1819-E1828 (2018). DOI: 10.1073/pnas.1720237115, Pubmed:

49. Shaw, P. \& Doonan, J. The nucleolus: playing by different rules? Cell Cycle 4, 102-105 (2005). DOI: $\underline{10.4161 / c c .4 .1 .1467}$, Pubmed: $\underline{15655371 .}$

50. Buchwalter, A. \& Hetzer, M. W. Nucleolar expansion and elevated protein translation in premature aging. Nat. Commun. 8, 328 (2017). DOI: 10.1038/s41467-017-00322-z, Pubmed: establishment of new nutritional symbionts in aphids' di-symbiotic systems. ISME J. 14, 259-273 (2020). DOI: 10.1038/s41396-019-0533-6, Pubmed: $\underline{31624345}$. 
615 53. Luan, J., Sun, X., Fei, Z. \& Douglas, A. E. Maternal inheritance of a single somatic animal cell

616 displayed by the bacteriocyte in the whitefly Bemisia tabaci. Curr. Biol. 28, 459-465.e3 (2018).

617 DOI: $10.1016 /$ j.cub.2017.12.041, Pubmed: 29395925.

618 54. Tremblay, E. \& Caltagirone, L. E. Fate of polar bodies in insects. Annu. Rev. Entomol. 18, 421-444 (1973). DOI: 10.1146/annurev.en.18.010173.002225.

55. Nardon, P., Lefevre, C., Delobel, B., Charles, H. \& Heddi, A. Occurrence of endosymbiosis in Dryophthoridae weevils: cytological insights into bacterial symbiotic structures. Symbiosis 33,

56. Bandi, C. \& Sacchi, L. Intracellular symbiosis in termites in Termites: Evolution, Sociality, $227-241$ (2002).

57. Heddi, A. \& Nardon, P. Sitophilus oryzae L.: a model for intracellular symbiosis in the Dryophthoridae weevils (Coleoptera). Symbiosis 39, 1-11 (2005).

58. Kanbe, T. \& Akimoto, S. I. Allelic and genotypic diversity in long $\square$ term asexual populations of

59. Tsuchida, T., Koga, R., Shibao, H., Matsumoto, T. \& Fukatsu, T. Diversity and geographic distribution of secondary endosymbiotic bacteria in natural populations of the pea aphid,

60. Ishikawa, A. et al. Juvenile hormone titre and related gene expression during the change of reproductive modes in the pea aphid. Insect Mol. Biol. 21, 49-60 (2012). DOI: $\begin{array}{llllll}\text { Acyrthosiphon } & \text { Misum. } & \text { Mol. } & \text { 11, 2002). } & \text { DOI: }\end{array}$ $\underline{10.1046 / j .1365-294 x .2002 .01606 . x}$, Pubmed: $\underline{12296954 .}$ 10.1111/j.1365-2583.2011.01111.x, Pubmed: 21988597.

61. Matsuda, N., Kanbe, T., Akimoto, S. I. \& Numata, H. Transgenerational seasonal timer for suppression of sexual morph production in the pea aphid, Acyrthosiphon pisum. J. Insect Physiol. 
101, 1-6 (2017). DOI: 10.1016/j.jinsphys.2017.06.008, Pubmed: 28610748.

62. Nozaki, T. \& Matsuura, K. Termite queens have disproportionately more DNA in their fat body cells: reproductive division of labor and endoreduplication. Entomol. Sci. 19, 67-71 (2016). DOI: 10.1111/ens.12156.

63. Nozaki, T. \& Matsuura, K. Evolutionary relationship of fat body endoreduplication and queen fecundity in termites. Ecol. Evol. 9, 11684-11694 (2019). DOI: 10.1002/ece3.5664, Pubmed: $\underline{31695878 .}$.

\section{Acknowledgements}

651 We thank S. Yorimoto, C. Chung, M. Suzuki, and other members of the laboratory of 652 Evolutionary Genomics, NIBB for their assistance and valuable discussions. We also thank A. Nakabachi and S. Koshikawa for technical advice, Functional Genomics Facility,

654 NIBB Core Research Facilities for the technical support, and Editage (www.editage.com) 655 for English language editing. This work was financially supported by the Japan Society 656 for the Promotion of Science to T.N. (Research Fellowship for Young Scientists No. 19J01756) and S.S. (KAKENHI 17H03717 and 20H00478).

658

\section{Author contributions}

660 T. N. and S. S. designed research; T. N. performed the experiment and analyzed data; T. N. 661 and S. S. wrote the original draft of the paper and both authors will contribute 662 substantially to revisions. 
bioRxiv preprint doi: https://doi.org/10.1101/2021.12.03.471054; this version posted December 3, 2021. The copyright holder for this preprint (which was not certified by peer review) is the author/funder, who has granted bioRxiv a license to display the preprint in perpetuity. It is made available under aCC-BY-NC-ND 4.0 International license.

663

\section{Declarations of interest}

665 There are no conflicts of interest to declare. 


\section{Figures and legends}
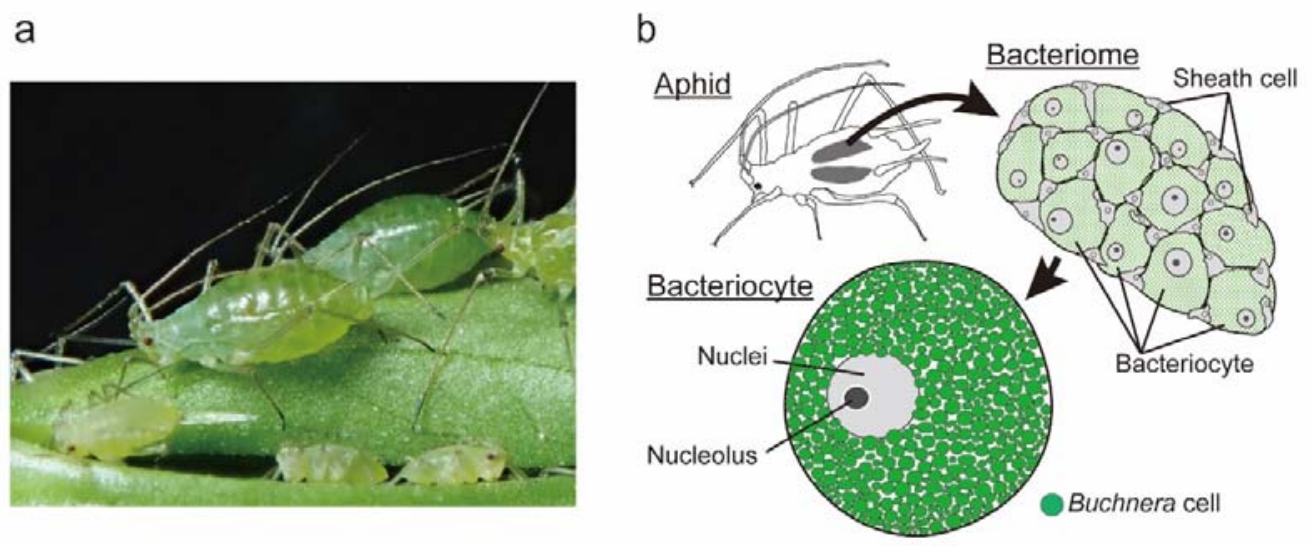

668 Figure 1. Intracellular symbiosis in the pea-aphid, Acyrthosiphon pisum. a a photograph

669 of pea-aphids (viviparous females). b Aphids harbor their bacterial symbionts in the

670 specialized organ, bacteriome. The organ contains two types of cells, bacteriocytes and

671 sheath cells. Bacteriocytes are symbiotic host cells that harbor Buchnera aphidicola in

672 the cytoplasm and are remarkably large (approximately $100 \mu \mathrm{m}$ in diameter); sheath cells

673 are much smaller than bacteriocytes and do not present Buchnera. The function of sheath

674 cells has not been well studied. Illustrations were drawn according to Koga et al. ${ }^{[21]}$. 


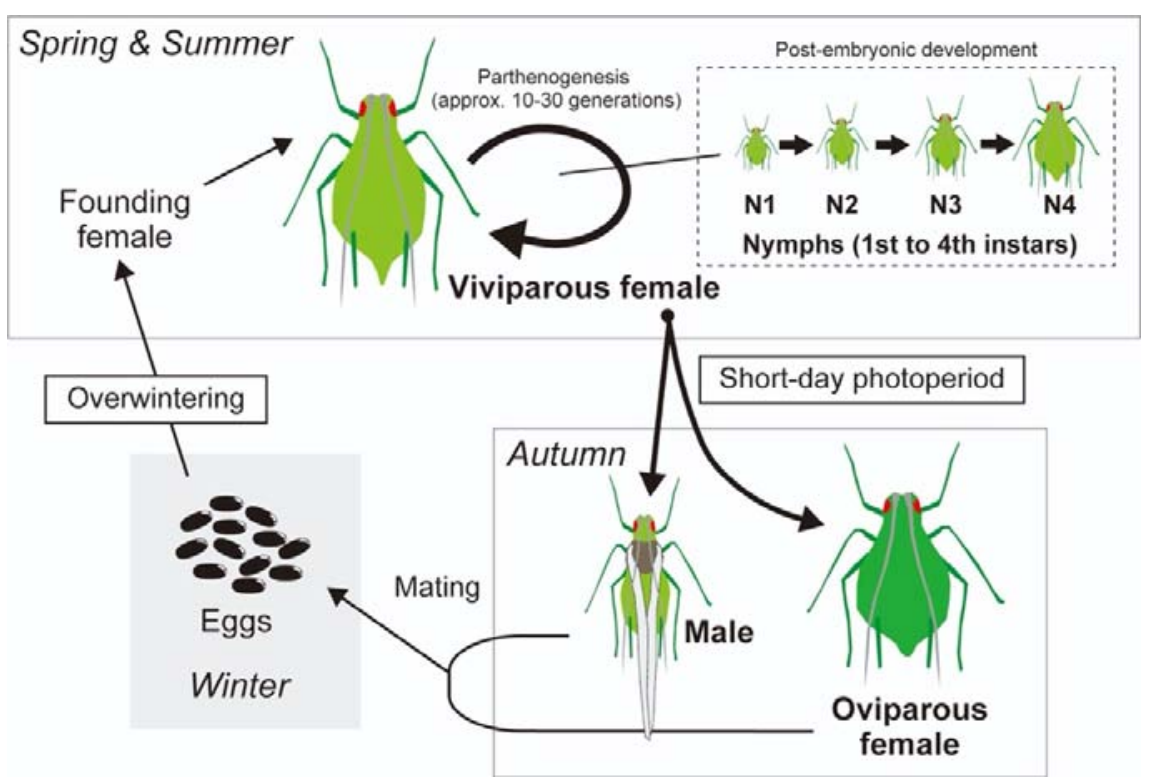

676 Figure 2. The life cycle and polymorphism of pea-aphids. In the field, viviparous

677 females are observed from spring to summer on their host plants and rapidly reproduce

678 through viviparous parthenogenesis. N1-4 represents the first to fourth instar nymphs.

679 Larviposited nymphs grow up to adults after molting four times. Oviparous females and

680 males emerge in autumn; they are induced by short-day photoperiod. Oviparous females

681 mate with males and produce eggs (sexual reproduction). All aphid morphs harbor $B$.

682 aphidicola inside of their bacteriocytes. Aphid morphs and developmental stages that we

683 have used for ploidy analysis of their bacteriocytes were bold lettered. Illustrations were

684 drawn according to Ogawa \& Miura $^{[30]}$. 

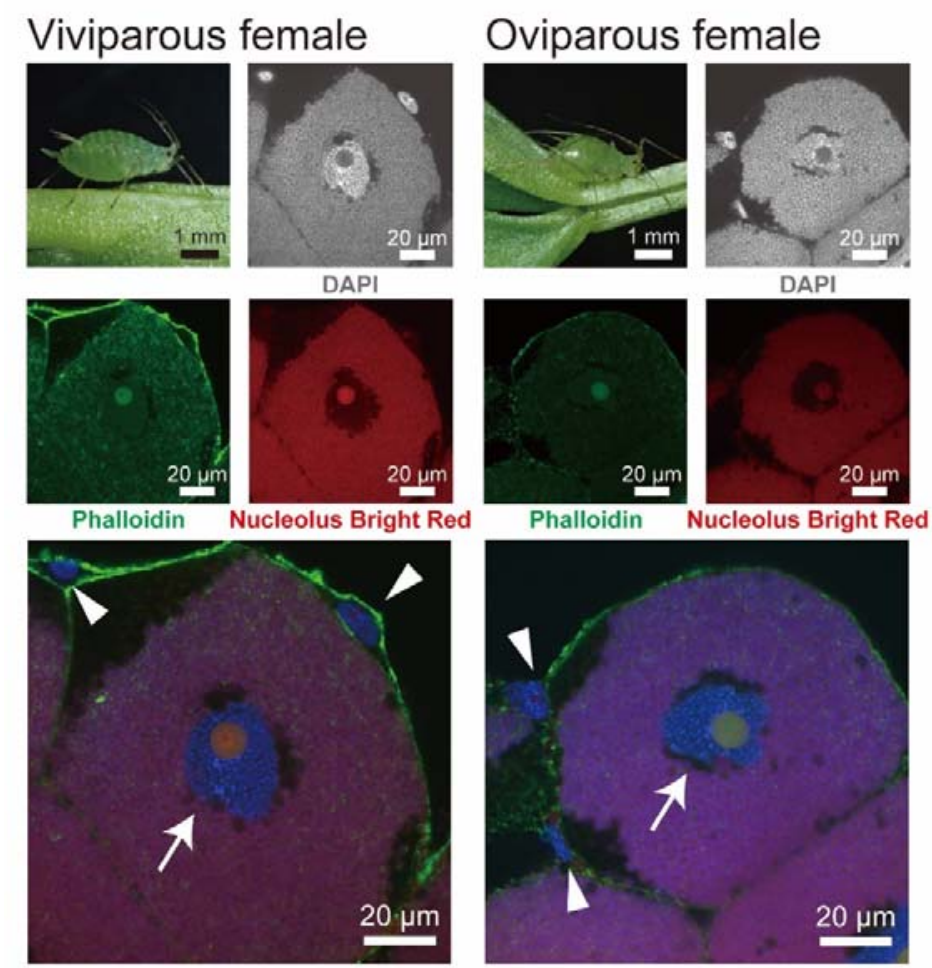

DAPI / Phalloidin / Nucleolus Bright Red

\section{Male}

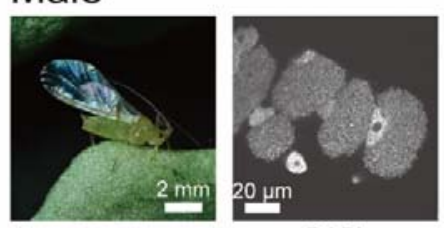

DAPI

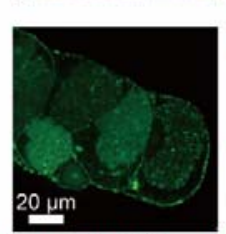

Phalloidin

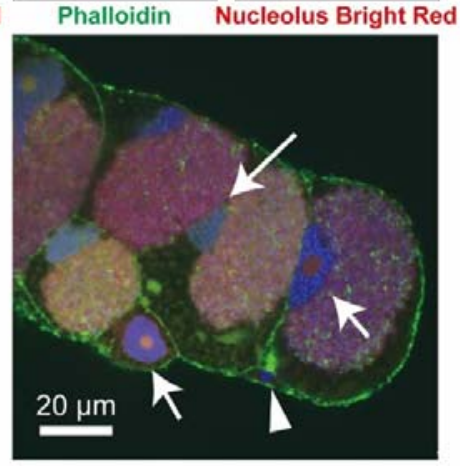

685

686 Figure 3. Morphology of bacteriocytes and sheath cells from each morph of aphids

687 visualized using DAPI/Phalloidin/Nucleolus Bright Red staining. DNA and F-actin were

688 stained by DAPI (gray or blue) and Phalloidin (green), respectively. The nucleolus, which

689 is the site of ribosome biogenesis, was visualized by Nucleolus Bright Red (red). This dye

690 binds RNA electrostatically, therefore the cytoplasm of bacteriocytes and Buchnera cells

691 were also stained. Bacteriocytes (white arrows) had single prominent nucleolus, and the

692 cell sizes were much larger than sheath cells (white arrowheads) in all aphid morphs. 

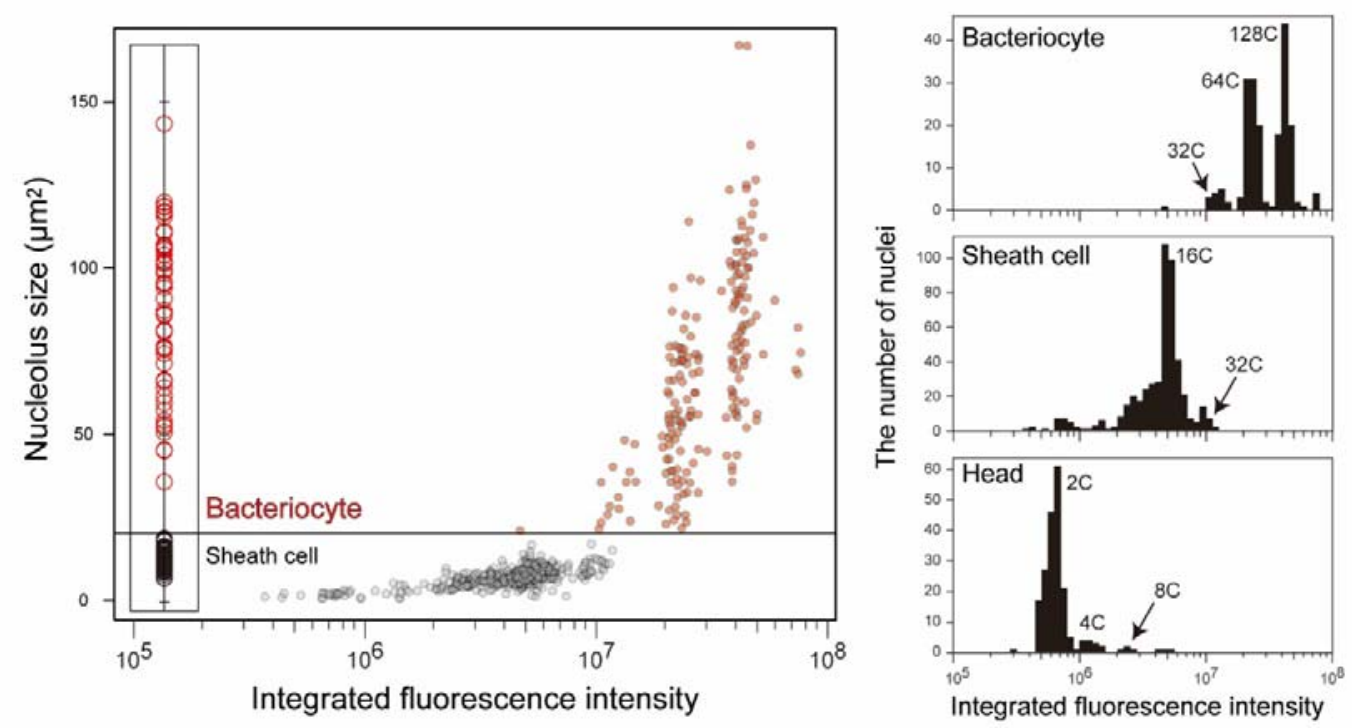

693

694 Figure 4. Ploidy analysis of aphid bacteriocytes using DAPI-fluorometry. A representative result from the analysis of adult viviparous females is presented. Isolated nuclei of bacteriome cells were stained using DAPI, image-captured with a CCD camera, and their integrated fluorescence intensity was measured using ImageJ software. Nuclei were categorized into "bacteriocytes" or "sheath cells," based on the size distribution of nucleolus (see Material and methods). Relative ploidy levels were calculated based on the data from head cells which are mainly diploid. Bacteriocytes of adult viviparous aphids consisted of $16 \mathrm{C}-256 \mathrm{C}$ cells, and $64-128$ cells were dominant, while sheath cells exhibited lower ploidy levels (mainly 16C). "C" means haploid genome size, for example, $2 \mathrm{C}=$ diploid and $8 \mathrm{C}=$ octoploid 


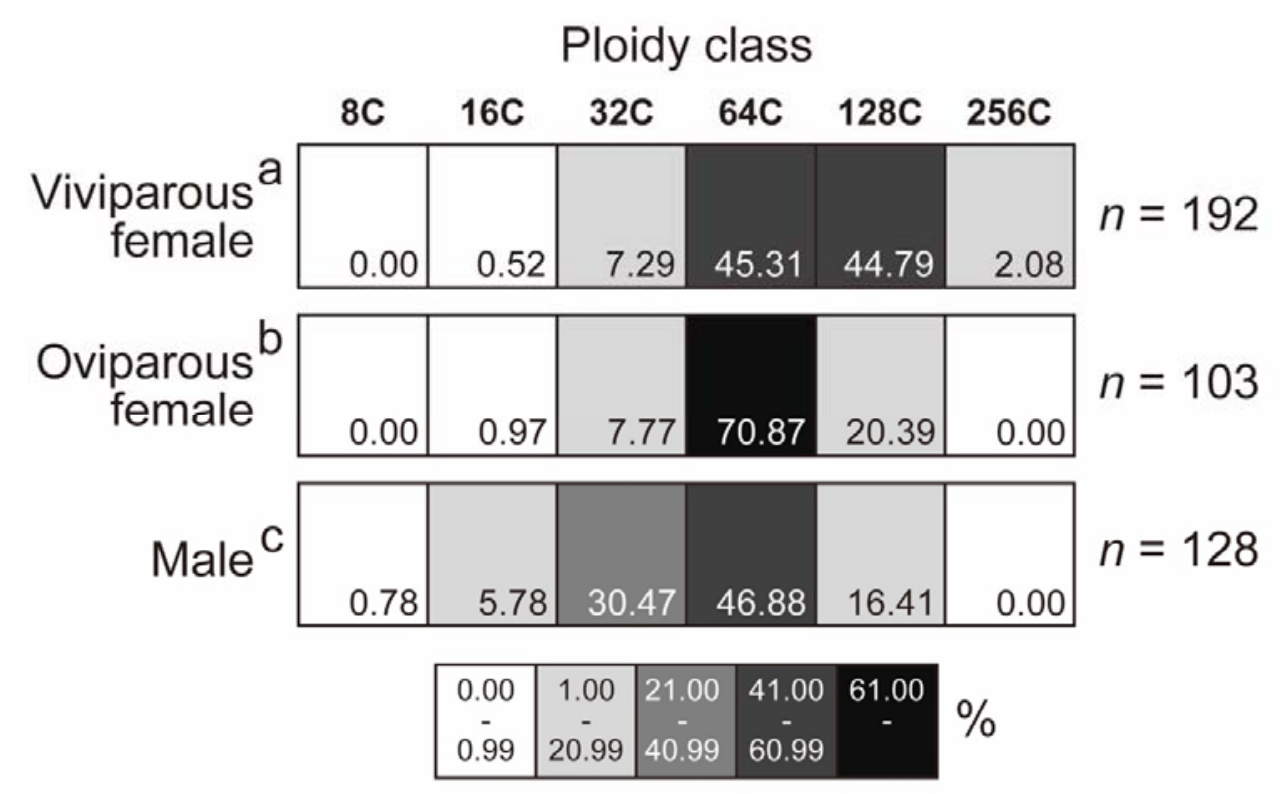

705 Figure 5. Ploidy distribution of bacteriocytes among aphid morphs, viviparous females,

706 oviparous females, and males. Sample size (numbers of bacteriocyte nuclei) is shown at

707 the right. Different letters with aphid categories indicate significant differences in the

708 median ploidy class (Brunner-Munzel test with Bonferroni adjustment, $p<0.05$ ).

709 Bacteriocytes of adult viviparous females in the pea-aphid were highly polyploid and

710 were mainly $64-128 \mathrm{C}$ cells. The cells of oviparous females and males were mainly $64 \mathrm{C}$

711 and 32-64C, respectively. The degree of polyploidy levels was highest in viviparous

712 females. 
a

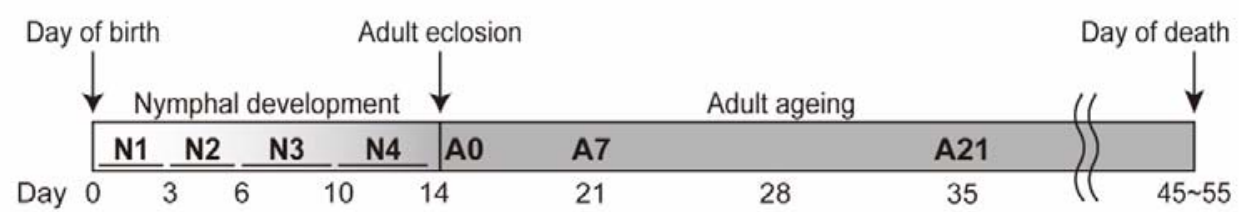

b

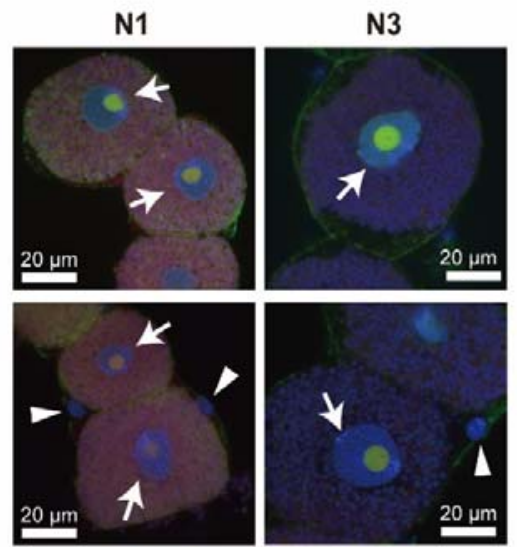

DAPI / Phalloidin Nucleolus Bright Red
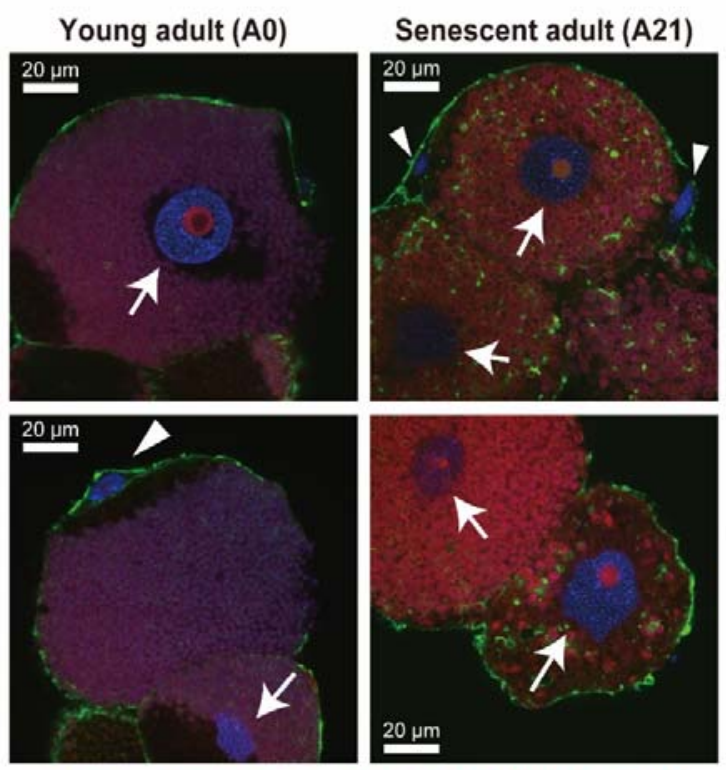

DAPI / Phalloidin / Nucleolus Bright Red

714 Figure 6. Developmental scheme and morphological changes of bacteriocytes during

715 post-embryonic development in viviparous females. a First-instar nymphs of viviparous

716 aphids molt four times during $13.73 \pm 0.32$ (mean \pm SEM, $n=16$ ) days at $16{ }^{\circ} \mathrm{C}$. After

717 adult eclosion, aphids live approximately 1 month under $16{ }^{\circ} \mathrm{C}$. N1-4 represents the first

718 to fourth instar nymphs. A0, A7, and A21 mean adult aphids at the day of eclosion, at 7

719 and 21 days after eclosion, respectively. b Confocal microscopic images of bacteriocytes

720 and sheath cells in each stage of viviparous females. N1 and N3 were selected and

721 presented as representatives of nymphal stages. A0 and A21 adults were presented as

722 young adults and senescent adults, respectively. DNA and F-actin were stained using

723 DAPI (blue) and Phalloidin (green), and nucleolus was visualized by Nucleolus Bright

724 Red (red). White arrows; nuclei of bacteriocytes, white arrowheads; nuclei of sheath 
bioRxiv preprint doi: https://doi.org/10.1101/2021.12.03.471054; this version posted December 3, 2021. The copyright holder for this preprint (which was not certified by peer review) is the author/funder, who has granted bioRxiv a license to display the preprint in perpetuity. It is made available under aCC-BY-NC-ND 4.0 International license.

725 cells. 


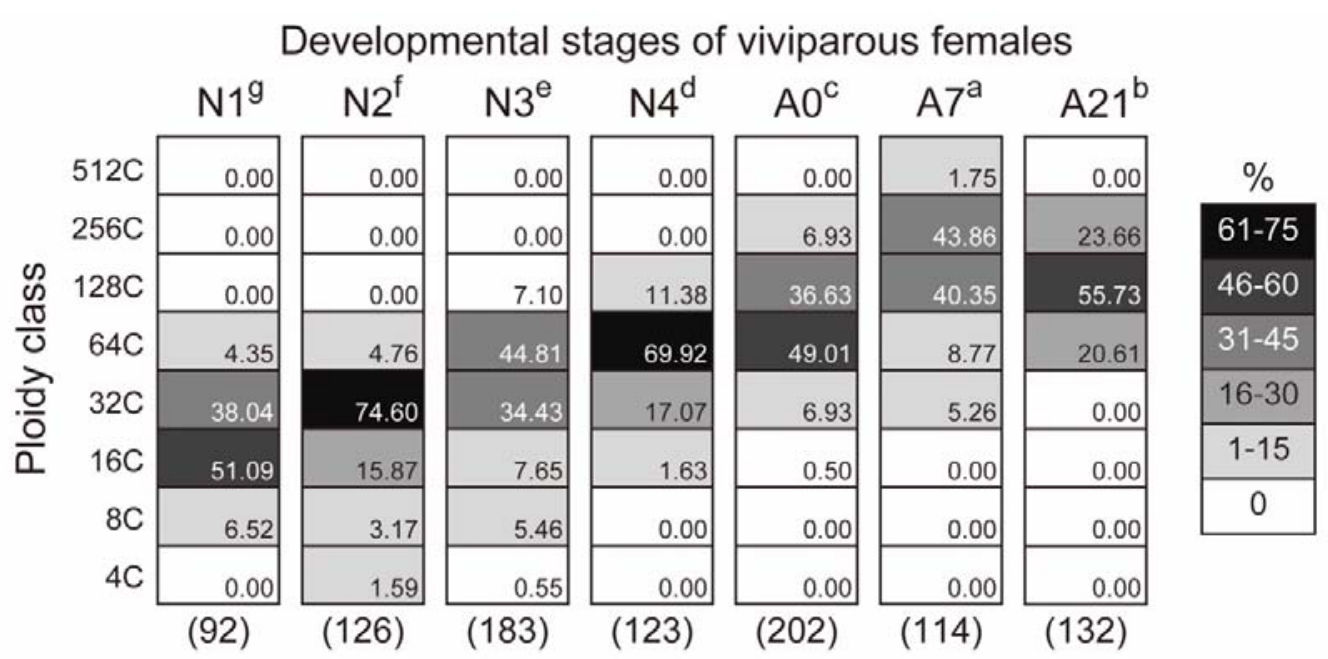

727 Figure 7. Ploidy distribution of bacteriocytes of each developmental stage of viviparous

728 aphids. Sample size (numbers of bacteriocyte nuclei) is shown below each column. N1-4

729 represents the first to fourth instar nymphs, and A0, A7 and A21 indicate 0-, 7-,

730 21-day-old adults. Different letters with aphid stages indicate significant differences in

731 the median ploidy class (Brunner-Munzel test with Bonferroni adjustment, $p<0.05$ ).

732 Bacteriocytes of adult viviparous females (A0-A21) in the pea-aphid were highly

733 polyploid (64-256C), while those of N1 nymphs were mainly 16C and 32C cells. 

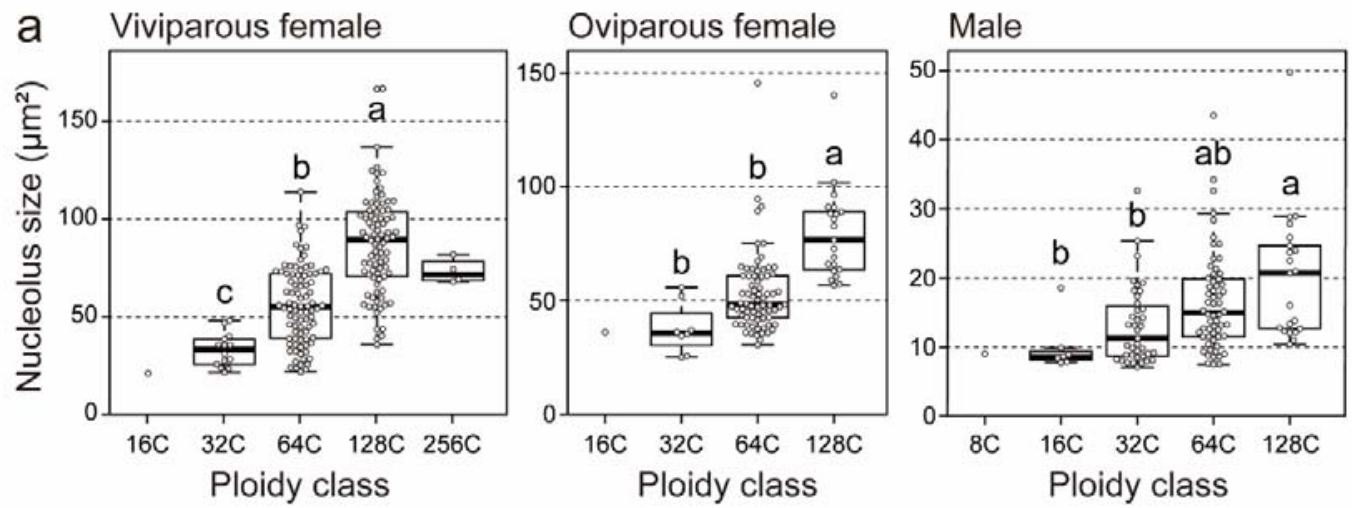

b

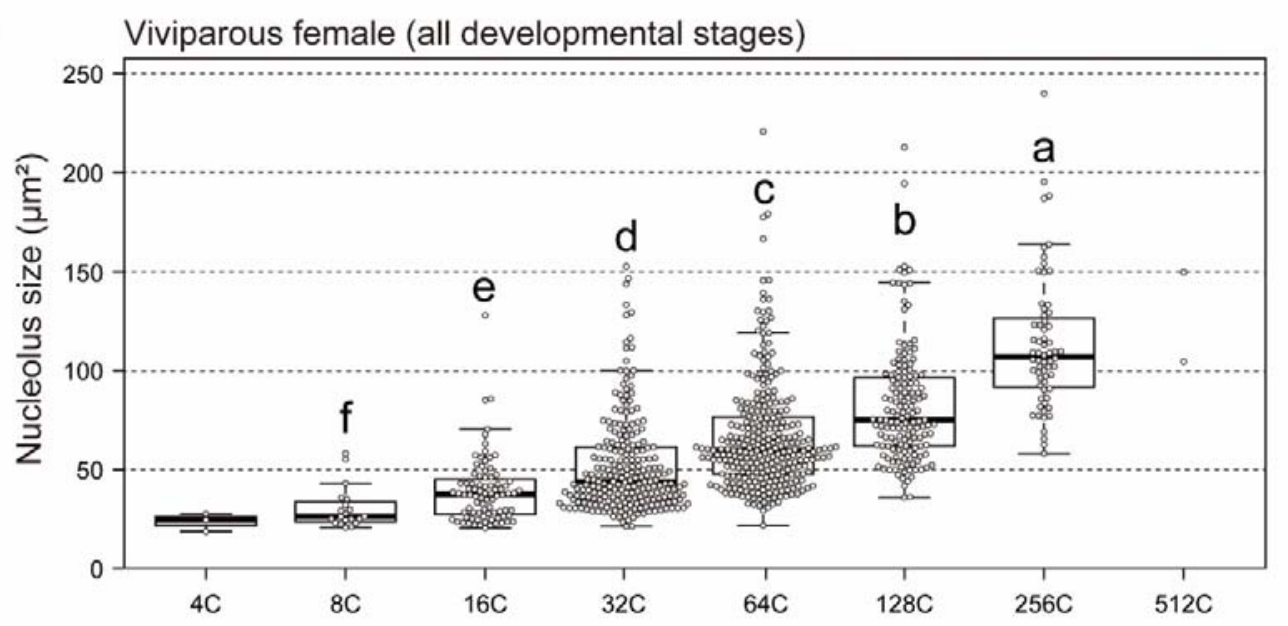

Ploidy class

735 Figure 8. The relationship between the size of nucleolus and ploidy levels of aphid

736 bacteriocytes. In the boxplots, central bold lines represent the medians, boxes comprise

737 the 25-75 percentiles and whiskers denote the range. a The size of nucleolus was

738 significantly different among ploidy class in all aphid morphs (LM with type II test; $p<$

7390.001 each). Different letters indicate significant differences (Tukey's test, $p<0.05$ ).

740 Note that $16 \mathrm{C} / 256 \mathrm{C}, 16 \mathrm{C}$, and $8 \mathrm{C}$ bacteriocytes in viviparous, oviparous females and 741 males, respectively, were excluded from these analyses due to the small sample size. b

742 Nucleolus size was significantly different among ploidy class in viviparous females

743 (LMM with type II test; $p<0.001$ ). Different letters indicate significant differences

744 (Tukey's test, $p<0.05$ ). Note that $4 \mathrm{C}$ and $512 \mathrm{C}$ were excluded from this analysis due to 
bioRxiv preprint doi: https://doi.org/10.1101/2021.12.03.471054; this version posted December 3, 2021. The copyright holder for this preprint (which was not certified by peer review) is the author/funder, who has granted bioRxiv a license to display the preprint in perpetuity. It is made available under aCC-BY-NC-ND 4.0 International license.

745 the small number. 